\title{
D
}

Recebido em 20/06/2017. Aprovado em 16/07/2017. Avaliado pelo sistema double blind peer review. Publicado conforme normas da ABNT.

\section{Práticas de Gestão do Conhecimento de recursos humanos em escolas públicas}

\author{
Arthur Gualberto Bacelar da Cruz Urpia \\ Marcio Pedro Cabral \\ Ely Mitie Massuda \\ Flávio Bortolozzi
}

Doutor em Economia. Centro Universitário de Maringá (UNICESUMAR) Brasil - arthurbacellar@yahoo.com.br Mestre em Gestão do Conhecimento nas Organizações. Centro Universitário de Maringá (UNICESUMAR) Brasil marciopedro2010@gmail.com

Doutora em História Econômica. Centro Universitário de Maringá (UNICESUMAR) Brasil - elymitie.m@gmail.com Doutor em Engenharia de Computação. Centro Universitário de Maringá (UNICESUMAR) Brasil - flavio.bortolozzi.53@gmail.com

\section{RESUMO}

O objetivo da presente pesquisa foi de analisar o nível de implantação e de alcance das práticas de Gestão do Conhecimento de recursos humanos em escolas públicas do município de Sarandi (PR). Para tal, metodologicamente, a pesquisa, que é exploratória, caracteriza-se como um estudo de caso múltiplo com abordagens quantitativa e qualitativa. Como instrumento de pesquisa empregado para a realização do diagnóstico da Gestão do Conhecimento nas escolas foi aplicado questionário desenvolvido pelo Instituto de Pesquisa Econômica Aplicada. Como principais resultados, inicialmente, através do cálculo do alfa de Cronbach, verificou-se que o nível de consistência dos dados obtidos varia de moderada para excelente, o que significa que as respostas decorrentes da aplicação do instrumento de diagnóstico aplicado têm uma alta confiabilidade. A partir do diagnóstico realizado, observou-se que o nível efetivo de implantação das práticas de Gestão do Conhecimento de recursos humanos é mediano, enquanto o seu nível efetivo de alcance é baixo. Estes resultados demonstram a necessidade de criação de medidas para a ampliação da implementação e alcance das práticas de Gestão do Conhecimento de recursos humanos nas escolas analisadas.

Palavras-chave: Gestão do Conhecimento. Práticas de Gestão do Conhecimento. Recursos Humanos. Ensino Público.

\section{Practices of knowledge management in human resources in public schools}

\begin{abstract}
The objective of this research was to analyze the level of implementation and reach of the Knowledge Management practices of human resources in public schools of the city of Sarandi (PR). The research methodology, which is exploratory, is characterized as a multiple case study with quantitative and qualitative approaches. The questionnaire, developed by the Institute of Applied Economic Research, was applied as a research tool used to carry out the Knowledge Management diagnosis in schools. The main results, initially, through the calculation of Cronbach's are highly reliable. Then, it was observed that, on average, the effective implementation level of Human Resources Knowledge Management practices is medium and, on average, the effective level of reach is low. These results demonstrate the need to create measures to expand the implementation and reach of the Knowledge Management practices of human resources in the analyzed schools.
\end{abstract}

Keywords: Knowledge management. Knowledge Management Practices. Human Resources. Public education. 


\title{
1 INTRODUÇÃO
}

Atualmente com os novos desafios da era da informação, Sánchez (2011) ressalta que a mudança de mentalidade das organizações sobre o valor do conhecimento evoluiu muito nos últimos tempos, podendo se afirmar que vivemos às portas da Sociedade do Conhecimento e do desenvolvimento qualitativo da Sociedade da Informação. Além disto, a Gestão do Conhecimento (GC) é um campo que permite ser aplicado a contextos educativos, que também busca a melhoria contínua de suas atividades. Estes grupos de "conhecimento" de ambientes educacionais podem ser beneficiados de alguns modelos de GC já existentes em outros tipos de organizações, assim como das pesquisas desenvolvidas neste domínio. Práticas de GC geram benefícios, sobretudo em campos tais como: as competências profissionais; o cooperativismo e satisfação; bem como da obtenção conhecimento e da informação comprovada. Com a mudança a GC passa a ser vista como um objeto importante e necessário para toda instituição, uma vez que já representa, em si, uma inovação. Ademais, as instituições têm buscado possibilidades para se converterem em organizações que apreciem o aprendizado, instituindo ambientes que promovam a criação e o compartilhamento de conhecimentos e ajustando-se ao meio cada vez mais agitado, no sentido de que vantagens competitivas necessitam ser reelaboradas de forma permanente.

Nesse contexto, as práticas de GC de recursos humanos agem nas organizações facilitando a transferência, a disseminação e o compartilhamento de informações e de conhecimento (BATISTA, 2006; BATISTA et al., 2014). No meio educacional observa-se que "[...] as práticas relacionadas à gestão de recursos humanos têm como objetivo auxiliar o gestor na construção de uma equipe capacitada e que contribua de forma natural para a aprendizagem organizacional" (BENTO et al., 2016, p. 5), sendo de grande valia para as instituições de ensino.

Diante disso, o objetivo geral deste trabalho foi de analisar o nível de implantação e de alcance das práticas de GC de recursos humanos em escolas públicas do município de Sarandi (PR).

\section{A GESTÃO DO CONHECIMENTO EM ORGANIZAÇÕES PÚBLICAS: ASPECTOS TEÓRICOS E PRÁTICAS}

Com a mudança do contexto socioeconômico, político, cultural e tecnológico, tem-se início o período denominado de 'era da informação'. Faz-se importante ressaltar que os elementos que lhe dão origem, traduzem-se em novas maneiras de pensar e de produzir, germinados desde a transição para a Modernidade, a partir do século XIV no continente europeu. Nessa conjuntura, somaram-se os resultados provenientes da Revolução Científica dos séculos XVI e XVII, ocasião em que foram difundidas as bases para a consolidação do método científico moderno (ALBAGLI, 1999). Ainda de acordo com Albagli (1999, p. 310):

\begin{abstract}
A chamada era da informação e do conhecimento, embora assumindo uma dimensão global, reflete: (a) a diferenciação entre distintas realidades culturais e projetos de sociedade, por parte de comunidades territoriais e segmentos sociais diversos; e (b) a desigualdade entre sociedades em diferentes estágios de desenvolvimento socioeconômico e tecnológico, ou entre economias avançadas e periféricas, bem como entre segmentos de diferentes níveis socioeconômicos no interior de uma mesma sociedade nacional.
\end{abstract}

Na 'era da informação', a GC passa ter uma importância cada vez maior para as empresas privadas, proporcionando-as vantagens competitivas. Para Batista (2006, p. 122), “[...] a gestão do conhecimento é a capacidade de a empresa armazenar e disponibilizar as informações de maneira segura, confiável e de fácil acesso". Sobre a importância da GC nas organizações, Stewart (2002, p. 47) afirma que "apenas por meio do conhecimento as empresas são capazes de se diferenciarem das concorrentes".

De acordo com Cavalcanti (2001), a abordagem com relação ao desempenho dos indivíduos nas organizações e sobre o valor do seu conhecimento alteraram-se, o que demandou novos formatos de gestão. Assim, no ambiente organizacional, perceber como a informação e o conhecimento defluem pela empresa é fundamental para o progresso continuado da mesma. Contudo, somente o entendimento sobre isso não torna possível a efetivação do desenvolvimento estruturado de GC. Nasce, a partir disso, a necessidade de elaboração de ferramentas, assim como modelos para medição da GC nas organizações. Para Davenport e Prusak (1999), só o conhecimento pode proporcionar uma vantagem competitiva sustentável para as organizações, pois as empresas encontram-se em contexto em que os ciclos de vida das inovações são curtos, pois o conhecimento gera retornos crescentes e dianteiras continuadas.

Assim, "o contexto da esfera privada, o desafio de produzir mais e melhor vai sendo suplantado pela necessidade permanente, de criar novos produtos, serviços, processos e sistemas gerenciais" (SCHLESINGER et al., 2008 , p. 6). Por outro lado, nas instituições da esfera pública, o movimento de transformações ocorre em um compasso mais vagaroso. A maior parte dessas instituições ainda conserva particularidades da administração burocrática e não é capaz de retornar com rapidez e qualidade às demandas de seus usuários. De acordo com Schlesinger et al. (2008, p. 6):

Esse tipo de administração foi desenvolvido em uma outra época, quando a sociedade funcionava em outro ritmo e as transformações ocorriam com menor rapidez. Assim, pode-se afirmar que, atualmente, existe um 
choque entre os valores da administração pública e os da nova economia. O resultado disso é a imagem tão difundida na sociedade, a da ineficiência e da má qualidade da administração pública.

Apesar disso, a administração pública, em todo corpo social, configura-se, ao mesmo tempo, importante e complexa, pois influencia muitos aspectos da vida em sociedade, afetando também áreas fundamentais, tais como a cultura, a educação e a saúde. Conforme Wiig (2000 apud SCHLESINGER et al., 2008, p. 6), "quando competente, pode contribuir na construção de uma grande sociedade. Por outro lado, um serviço público incompetente pode levar a sociedade à ruína social. Isso revela, portanto, a sua grande importância nos dias de hoje".

Mas surge, de acordo com Schlesinger et al. (2008, p. 6-7), "o papel da gestão do conhecimento dentro da administração pública, que transcende a finalidade de melhoria de desempenho das organizações". Assim sendo, deduz-se que com tais modificações internas no estilo de gestão organizacional, todo corpo social também ganha, uma vez que será influenciado pelos avanços e melhorias na qualidade dos serviços prestados.

\subsection{As práticas de gestão do conhecimento de recursos humanos}

O ambiente organizacional, de forma geral, ainda apresenta dificuldades na identificação, armazenamento e disseminação dos seus conhecimentos envolvidos com as práticas de GC. Isso se dá, principalmente, pelo desconhecimento das mesmas, assim como suas funcionalidades e, consequentemente, sua potencialidade em contribuir com a organização. Batista et al. (2005) apresentam algumas práticas que demonstram a forma pela qual as organizações gerenciam de maneira proativa o conhecimento. Assim sendo, consideram-se práticas de GC as atividades que reúnem as seguintes características, de acordo com Batista et al (2005, p. 15):

i) são executadas regularmente; ii) sua finalidade é gerir a organização; iii) baseiam-se em padrões de trabalho; e iv) são voltadas para produção, retenção, disseminação, compartilhamento ou aplicação do conhecimento dentro das organizações, e na relação destas com o mundo exterior.

A partir disso, é importante ressaltar que a escolha da prática, bem como sua caracterização adequada à necessidade institucional, torna-se imprescindível para uma contribuição efetiva para a organização no que tange à melhoria de seus processos de GC. O Quadro 1 apresenta importantes práticas de GC de recursos humanos.

Quadro 1 - Práticas de GC de recursos humanos

\begin{tabular}{|l|l|}
\hline \multicolumn{1}{|c|}{ Prática } & \multicolumn{1}{c|}{ Conceito } \\
\hline $\begin{array}{l}\text { Comunidades } \\
\text { de prática ou } \\
\text { Comunidades } \\
\text { de } \\
\text { conhecimento }\end{array}$ & $\begin{array}{l}\text { São grupos informais e interdisciplinares de pessoas unidas em torno de um interesse } \\
\text { comum. As Comunidades de prática são criadas a partir de alianças de pessoas formadas } \\
\text { intencional ou espontaneamente para compartilhar, criar habilidades comuns, } \\
\text { conhecimento e experiências. As comunidades são auto-organizadas a fim de permitir a } \\
\text { colaboração de pessoas internas ou externas à organização; propiciam o veículo e o } \\
\text { contexto para facilitar a transferência de melhores práticas e o acesso a especialistas, bem } \\
\text { como a reutilização de modelos, do conhecimento e das lições aprendidas. }\end{array}$ \\
\hline Coaching & $\begin{array}{l}\text { O coaching é similar ao mentoring, mas o coach não participa da execução das atividades; } \\
\text { faz parte de processo planejado de orientação, apoio, diálogo e acompanhamento, alinhado } \\
\text { às diretrizes estratégicas. }\end{array}$ \\
\hline Mentoring & $\begin{array}{l}\text { O objetivo do mentoringé o desenvolvimento humano fundamental. O mentor investe } \\
\text { tempo, energia e esforço de transferir conhecimento para ajudar o crescimento e o } \\
\text { desenvolvimento das habilidades de uma outra pessoa. Nessa relação, o mentor procura } \\
\text { apoiar e direcionar por meio de atitudes positivas como integridade, compromisso, } \\
\text { experiência e perseverança. Existem quatro tipos de mentores: o conselheiro, o intelectual, o } \\
\text { formador e o consultor organizacional. }\end{array}$ \\
\hline
\end{tabular}

Fonte: Elaborado pelos autores com base em Batista (2012) e Young (2010).

Pode-se observar que a prática de GC, além de estar relacionada às pessoas, vincula-se a ações desenvolvidas em um contexto organizacional. No entanto, essas ações podem ser auxiliadas por acessórios alternativos, conhecidas por "ferramentas". Observa-se que a definição do termo "ferramenta" se refere, basicamente, a um instrumento, por meio do qual o indivíduo realiza uma ação que é facilitada pela utilização deste. Assim, pode-se entender que a ferramenta de GC consiste naquela por meio da qual o colaborador poderá concretizar ações e/ou processos de GC, ou seja, práticas de GC. 


\section{PROCEDIMENTOS METODOLÓGICOS}

Para atender ao objetivo geral, foi realizado um diagnóstico da GC nas escolas situadas na cidade de Sarandi que são participantes do Programa de Excelência na Educação Básica (PEEB). Esse programa é desenvolvido pela UniCesumar Empresarial desde 2013. Segundo Cassiano, Barbosa e Macuch (2015, p. 20), o PEEB “[...] tem por objetivo principal assessorar escolas em sua prática docente com o intuito de melhorar o processo de ensino-aprendizagem". Para tal, realiza consultoria e assessoria pedagógica, gratuitamente, a municípios das regiões Norte e Noroeste do Estado do Paraná.

Quanto ao procedimento técnico, a pesquisa caracteriza-se como estudo de caso múltiplo, de natureza exploratória com abordagens qualitativa e quantitativa. Como instrumento de pesquisa foi aplicado um questionário desenvolvido pelo Instituto de Pesquisa Econômica Aplicada (IPEA). O questionário aplicado - que foi amplamente utilizado em diversos estudos (BATISTA, 2006, 2012) refere-se a uma lista com vinte e sete práticas de GC que “[...] foi elaborada a partir de exemplos concretos observados em organizações de todo o mundo, englobando aplicações práticas, técnicas, processos e ferramentas" (BATISTA, 2006, p. 12).

A aplicação do questionário se deu no dia 23 de junho de 2016 em Seminário promovido por meio de parceria entre a UniCesumar Empresarial, que coordena o PEEB, e o Programa de Pós-Graduação em Gestão do Conhecimento nas Organizações da UniCesumar (PPGGCO). Esse Seminário teve também como objetivo capacitar os gestores das escolas a respeito do tema de GC e, mais especificamente, sobre as vinte e sete práticas de GC que compõem o questionário aplicado. É importante salientar que o questionário foi adaptado, pois foi incluída uma coluna contendo a descrição de cada uma das práticas.

Seguindo a classificação utilizada por Batista $(2006,2012)$, as práticas e ações contidas no questionário podem ser agrupadas em três categorias que estão representadas no Quadro 2.

Quadro 2 - Categorias das práticas e ações contidas no instrumento de coleta de dados

\begin{tabular}{|l|l|}
\hline \multicolumn{1}{|c|}{ Categorias } & \multicolumn{1}{c|}{ Definições } \\
\hline $\begin{array}{l}\text { Práticas e ações relacionadas aos aspectos } \\
\text { de gestão de recursos humanos. }\end{array}$ & $\begin{array}{l}\text { Tais práticas facilitam a transferência, a disseminação e o } \\
\text { compartilhamento de informações e de conhecimento. }\end{array}$ \\
\hline $\begin{array}{l}\text { Práticas e ações ligadas à estruturação dos } \\
\text { processos organizacionais. }\end{array}$ & $\begin{array}{l}\text { Estas práticas e ações funcionam como facilitadores da } \\
\text { geração, retenção, organização e disseminação do } \\
\text { conhecimento organizacional. }\end{array}$ \\
\hline $\begin{array}{l}\text { Práticas e ações cujo foco central é a base } \\
\text { tecnológica e funcional }\end{array}$ & $\begin{array}{l}\text { Estas práticas servem de suporte à GC organizacional, } \\
\text { incluindo a automação da gestão da informação, dos } \\
\text { aplicativos e das ferramentas de TI para captura, difusão e } \\
\text { colaboração. }\end{array}$ \\
\hline
\end{tabular}

Fonte: Elaborado pelos autores com base em Batista $(2006,2012)$.

Como o presente estudo visa diagnosticar a área de processos organizacionais, apenas as práticas e ações da segunda categoria serão analisadas. O questionário que foi respondido pelos coordenadores contempla a indicação de estágio de implantação por meio de uma escala de zero a quatro e, outra escala de um a quatro referindo-se ao alcance que se pretende obter dentro da organização, pelo estágio de implantação e o seu alcance, conforme segue:

a) Estágio de implantação: [0]: não existem planos para a implementação da prática; [1]: existem ações planejadas para a implementação da prática no futuro; [2]: a prática está em processo de implementação; [3]: a prática já está implementada, e; [4]: a prática já está implementada e apresenta resultados importantes e relevantes para a organização.

b) Alcance: [1]: iniciativas isoladas dentro da organização; [2]: alguns departamentos usam a prática; [3]: muitos departamentos usam a prática, e; [4]: amplamente disseminada na organização.

Para a análise de consistência dos dados obtidos pela aplicação dos questionários, foi calculado o alfa de Crobanch por meio do Programa Microsoft Excel versão 2010, a partir do método do cálculo das variâncias. Tal como Hora, Monteiro e Arica (2010), foi realizado o cálculo do alfa via planilha do Excel ao invés dos pacotes estatísticos profissionais disponíveis, que fazem cálculos similares (tal como o SPSS), pelo motivo de acompanhamento do processo de cálculo e purificação da escala.

O alfa de Cronbach "é um índice utilizado para medir a confiabilidade do tipo consistência interna de uma escala, ou seja, para avaliar a magnitude em que os itens de um instrumento estão correlacionados" (ALMEIDA; SANTOS; COSTA, 2010, p. 6), sendo considerado a estatística mais usada para medir a confiabilidade de um questionário. Faz-se importante salientar que a confiabilidade da escala está relacionada com a isenção de erros aleatórios, enquanto a validade da escala está relacionada ao fato do instrumento realmente medir aquilo que se propõe a medir (HORA; MONTEIRO; ARICA, 2010).

O valor de alfa é afetado pelo número de elementos que constitui uma escala. Contudo, se o número de elementos for aumentado, amplia-se também a variância. Ou seja, o valor de alfa é alterado de acordo com a 
população na qual se aplica a escala. Segundo Streiner (2003 apud ALMEIDA; SANTOS; COSTA, 2010, p. 6), “[...] o coeficiente alfa de Cronbach é uma propriedade inerente do padrão de resposta da população estudada, não uma característica da escala por si só". A Tabela 1 apresenta a escala utilizada para a análise da qualificação da consistência dos dados segundo o alfa de Cronbach.

\begin{tabular}{cc} 
Tabela 1 - Qualificação da consistência segundo o alfa de Cronbach. \\
\hline Intervalo & Consistência \\
\hline$a<0,6$ & Fraca \\
$0,6 \leq a<0,7$ & Moderada \\
$0,7 \leq a<0,8$ & Boa \\
$0,8 \leq a<0,9$ & Muito Boa \\
$a \geq 0,9$ & Excelente \\
\hline
\end{tabular}

Fonte: Elaborado pelos autores a partir de Loeschi e Hoeltgebaum (2012).

No que se refere à análise dos resultados referentes ao nível efetivo de implantação das práticas selecionadas, foram examinadas apenas as respostas relacionadas aos níveis 3 (a prática já está implantada) e 4 (a prática já está implantada e apresenta resultados importantes e relevantes para a organização) da escala de estágio de implantação.

Já para a análise do resultado em relação ao nível efetivo de alcance das práticas selecionadas, foram analisadas também apenas as respostas relacionadas aos níveis 3 (muitos departamentos usam a prática) e 4 (amplamente disseminada na organização) da escala do estágio de alcance, isto tendo-se em vista que apenas as respostas desses dois níveis indicam um efetivo alcance das práticas de GC.

Desta forma, para a análise do nível efetivo de implantação e alcance das práticas de GC, tal escala foi elaborada (Tabela 2), com os parâmetros sendo criados de forma arbitrária, no entanto, verificou-se como sendo mais conveniente.

Tabela 2 - Escala para análise do nível efetivo de implantação e alcance das práticas de GC.

\begin{tabular}{cc}
\hline Nível efetivo de implantação e alcance & Estágios 3+4 \\
\hline Nível baixo & Entre 0 a $39 \%$ \\
Nível médio & Entre $40 \%$ a $60 \%$ \\
Nível alto & Acima de $60 \%$ \\
\hline
\end{tabular}

Fonte: Elaboração própria (2017).

Para a análise dos resultados coletados pelo questionário, uma abordagem quantitativa foi aplicada. Os resultados foram apurados através de técnicas de estatística descritiva, tais como a análise de distribuição de frequência relativa dos dados. A organização dos dados foi realizada por meio do Programa Microsoft Excel versão 2010.

\section{RESULTADOS E DISCUSSÃO}

Para análise de consistência, inicialmente, foi realizada a tabulação dos dados, com cada uma das vinte e sete práticas contidas no instrumento de diagnóstico do IPEA sendo transformadas em itens.

\subsection{Análise de consistência dos dados do questionário}

O valor do alfa de Cronbach sobre os vinte e sete itens que representam o nível de implantação de todas as práticas contidas no instrumento de diagnóstico do IPEA foi de 0,9675 , valor que representa um nível de consistência excelente segundo a escala de Loeschi e Hoeltgebaum (2012). Já o valor do alfa do Cronbach sobre os vinte e sete itens que representam o nível de alcance foi de 0,9442, valor que também representa um nível de consistência excelente.

Em seguida, foi realizada uma nova tabulação apenas com as sete práticas que representam a categoria de recursos humanos. As práticas são: comunidade de prática/comunidade de conhecimento, mentoring, coaching, fóruns (presenciais e virtuais)/listas de discussão, educação corporativa, universidade corporativa e narrativas. Cada uma dessas práticas foi transformada em itens para o cálculo do alfa de Cronbach. Para os sete itens que representam o nível de implantação das práticas de recursos humanos, o alfa de Cronbach foi de 0,8814, valor que também representa um nível de consistência excelente. Já para os sete itens que representam o nível de alcance das práticas de recursos humanos, o alfa de Cronbach foi de 0,6272, que representa um nível de consistência apenas moderada, de acordo com a escala de Loeschi e Hoeltgebaum (2012).

Diante do resultado encontrado, buscou-se o método de purificação da escala para aumentar a confiabilidade da medição. O método de purificação é realizado através do "[...] recalculo do coeficiente de 
confiabilidade, desconsiderando um único item, e observando o comportamento do mesmo. Ao final, sumariza-se a purificação eliminando todos os itens cuja eliminação contribui para o aumento da confiabilidade da medição" (HORA; MONTEIRO; ARICA, 2010, p. 13). A Tabela 3 apresenta o recálculo do coeficiente de alfa de Cronbach ao se desconsiderar cada um dos sete itens pertencentes às práticas de GC de recursos humanos.

Tabela 3 - Método de purificação da escala.

Omissão de variáveis

\begin{tabular}{c|c}
\hline Variável & Valor de $\mathbf{a}$ \\
\hline Q1 & 0,6355 \\
Q2 & 0,6101 \\
Q3 & 0,5900 \\
Q4 & 0,6424 \\
Q5 & 0,3713 \\
Q6 & 0,5870 \\
Q7 & 0,6065 \\
\hline
\end{tabular}

Fonte: Elaboração própria (2017).

Tal como pode ser verificado pela Tabela 3, o valor do alfa de Cronbach para os sete itens que representam o nível de alcance das práticas de recursos humanos só seria ampliado caso fossem excluídos a primeira variável (Q1), algo que faria com que o valor de alfa de Cronbach aumentasse para 0,6355. Excluindo-se a quarta variável (Q4), o valor de alfa de Cronbach passaria para 0,6424. Como em nenhuma das duas situações o nível de consistência deixaria de ser moderado e dada a importância das duas variáveis para escala, optou-se por manter todas as variáveis.

A partir do cálculo do alfa de Cronbach tanto para todos os vinte e sete itens do instrumento de diagnóstico para os níveis de implantação e alcance quanto para apenas os sete itens da categoria de recursos humanos também para os níveis de implantação e alcance, verificou-se que o nível de consistência dos dados obtidos variou de moderada (para os sete itens que representam o nível de alcance das práticas de recursos humanos) para excelente (os demais casos), o que significa que as respostas decorrentes da aplicação do instrumento de diagnóstico aplicado têm uma alta confiabilidade. Diante da validade da escala e da sua confiabilidade, observa-se que a pesquisa realizada possui uma grande robustez.

\subsection{Análise do estágio de implantação das práticas}

Dentro do contexto educacional, observa-se que "[...] as práticas relacionadas à gestão de recursos humanos têm como objetivo auxiliar o gestor na construção de uma equipe capacitada e que contribua de forma natural para a aprendizagem organizacional" (BENTO et al., 2016, p. 5).

Entretanto, mesmo diante da importância que essas práticas possuem para uma instituição de ensino, os resultados da pesquisa mostram que, na média, o nível efetivo de implantação dessas práticas é mediano (35\%). $\mathrm{A}$ Tabela 4 apresenta o nível de implantação das ações e práticas de recursos humanos.

Tabela 4 - Estágio de implantação das ações ou práticas de recursos humanos

\begin{tabular}{|c|c|c|c|c|c|c|}
\hline \multirow{2}{*}{ Prática } & \multicolumn{6}{|c|}{ Estágio de implantação } \\
\hline & 0 & 1 & 2 & 3 & 4 & $\mathbf{N} / \mathbf{R}$ \\
\hline Comunidades de prática/comunidades de conhecimento & $30 \%$ & $50 \%$ & $20 \%$ & $0 \%$ & $0 \%$ & $0 \%$ \\
\hline Mentoring & $20 \%$ & $20 \%$ & $20 \%$ & $20 \%$ & $20 \%$ & $0 \%$ \\
\hline Coaching & $30 \%$ & $20 \%$ & $20 \%$ & $20 \%$ & $0 \%$ & $10 \%$ \\
\hline Fóruns (presenciais e virtuais)/listas de discussão & $30 \%$ & $0 \%$ & $30 \%$ & $40 \%$ & $0 \%$ & $0 \%$ \\
\hline Educação corporativa & $20 \%$ & $0 \%$ & $10 \%$ & $60 \%$ & $10 \%$ & $0 \%$ \\
\hline Universidade corporativa & $20 \%$ & $0 \%$ & $10 \%$ & $50 \%$ & $10 \%$ & $10 \%$ \\
\hline Narrativas & $30 \%$ & $0 \%$ & $50 \%$ & $10 \%$ & $0 \%$ & $10 \%$ \\
\hline Médias & $\mathbf{2 6 \%}$ & $13 \%$ & $\mathbf{2 3} \%$ & $\mathbf{2 9} \%$ & $6 \%$ & $4 \%$ \\
\hline
\end{tabular}

Fonte: Elaborado pelos autores (2017)

Nota: 0 - não existem planos de implantação; 1 - planejada para o futuro; 2 - em processo de implantação; 3 - já está implantada; 4 - implantada e apresentando resultados relevantes; e $n / r$ - não responderam.

Dentre as práticas analisadas, merecem destaque as seguintes: educação corporativa e universidade corporativa. A prática educação corporativa que possui um nível efetivo de implantação alto (Gráfico 1), "compreende processos de educação continuada estabelecidos com vistas à atualização de pessoal de maneira uniforme em todas as áreas da organização" (BATISTA, 2006, p. 14). Com isto, possibilita às organizações valorizar a educação continuada e considerar seus empregados como parte de seu capital (MEISTER, 1999). 
Gráfico 1 - Nível efetivo de implantação das práticas de recursos humanos

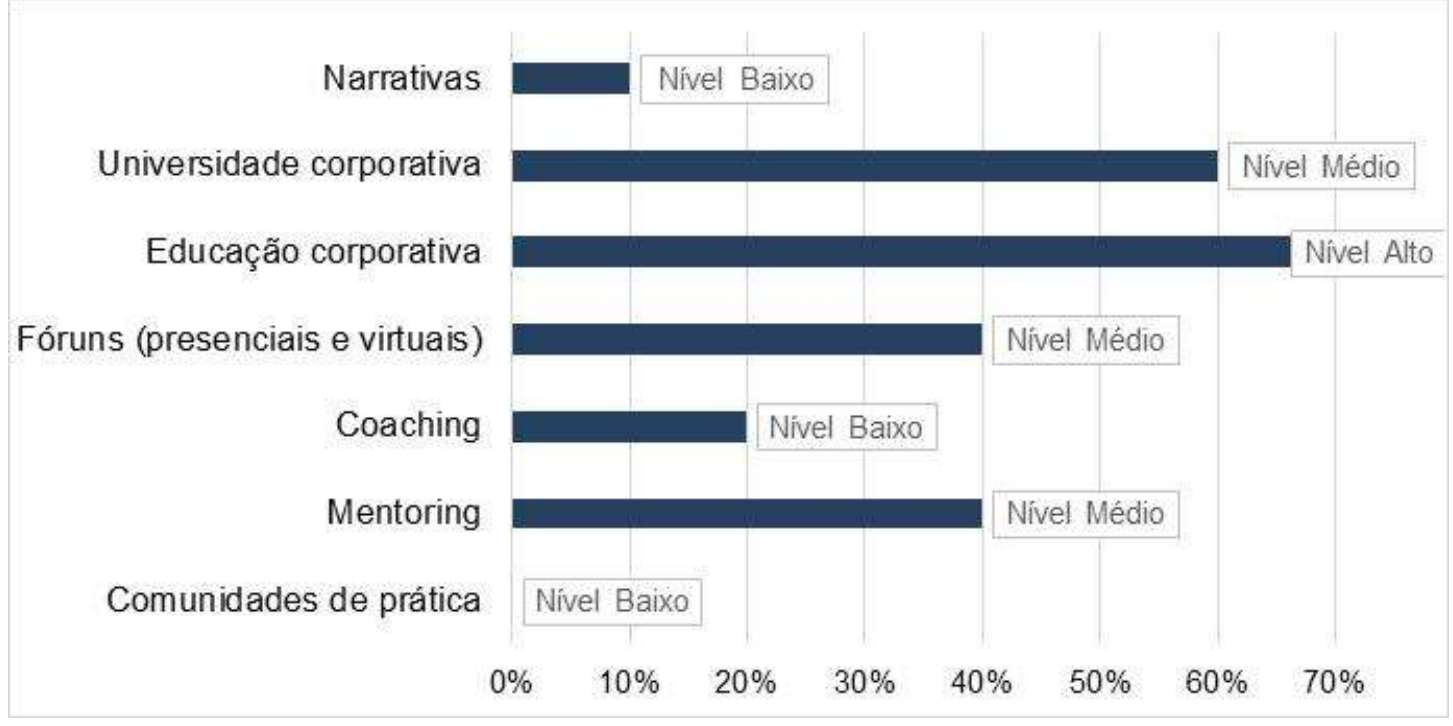

Fonte: Elaborado pelos autores (2017).

Dessa forma, essa prática contribui para melhorar o processo de aprendizagem das instituições de ensino estudadas, ao criar e estimular a disseminação do conhecimento organizacional. Já a prática universidade corporativa é caracterizada por um processo de educação continuada (tais como cursos técnicos e palestras), que objetiva o desenvolvimento de habilidades técnicas, de comportamentos e atitudes (BENTO et al., 2016). Essa prática, que possui um nível efetivo de implantação médio (Gráfico 1), também favorece a educação continuada e, com isto, a melhoria da aprendizagem.

Em contexto educacional, tem-se que a educação corporativa e a universidade corporativa remetem a organização e implementação de uma instituição de ensino, voltada para a promoção da disseminação e compartilhamento da informação e do conhecimento com o objetivo de incentivar e proporcionar a formação daqueles que usufruírem deste espaço (URPIA et al, 2016, p. 84).

Portanto, essas duas práticas oferecem importantes benefícios para as instituições de ensino analisadas e precisam ser cada vez mais incentivadas e consolidadas.

A prática de fóruns (presenciais e virtuais) ou listas de discussão também apresentou um nível efetivo de implantação médio (40\%), tal como pode ser observado no Gráfico 1. Essa prática, dentro de um contexto educacional, constitui-se como espaços que permitem a disseminação da informação e contribuem para a resolução de problemas. Entretanto, para $30 \%$ dos gestores que participaram da pesquisa, não há planos para implantação dessa prática em suas instituições, o que demonstra a necessidade de criação de medidas para ampliar a implantação dessa prática nas instituições analisadas.

A prática de mentoring, que também apresentou um nível efetivo de implantação médio (40\%), visa o desenvolvimento do capital humano, pois o mentor transfere conhecimento para ajudar o crescimento e o desenvolvimento das habilidades de outra pessoa (BATISTA, 2012). Dessa forma, essa prática, dentro do contexto educacional, contribui para o compartilhamento de experiências e geração de conhecimentos, melhorando a aprendizagem e a qualidade da educação. Através da Tabela 4, observa-se que as respostas dos gestores das instituições pesquisadas foram igualmente distribuídas em cada estágio de implantação, com exatos $20 \%$. Isso demonstra uma necessidade de criação de medidas para consolidar a prática de mentoring nas escolas analisadas, ampliando o nível efetivo de implantação dessa prática (níveis 3 e 4).

A prática de coaching é vista como similar à prática de mentoring, com a ressalva de que o coach não participa da execução das tarefas (BATISTA, 2006). Dentro do contexto educacional, um coach pode ser visto como um profissional que será levado à escola para passar experiência e conhecimento para os professores e demais funcionários, ampliando o nível de conhecimento das escolas. Apesar da importância dessa prática, observa-se que o nível efetivo de implantação é baixo, tal como demonstrado no Gráfico 1. Além disso, verifica-se, na Tabela 4, que $30 \%$ dos respondentes informaram que sequer há planos para implantação dessa prática.

Narrativas (Storytelling), segundo Batista (2006, p. 15), são "técnicas utilizadas em ambientes de gestão do conhecimento para descrever assuntos complicados, expor situações e/ou comunicar lições aprendidas ou, ainda, interpretar mudanças culturais". Desta forma, a prática é vista como sendo eficaz para a disseminação do conhecimento, isto por exigir um tempo menor de aplicação e uma maior interação com os receptores (BENTO et al., 2016). A partir dos dados coletados, verifica-se que o nível efetivo de implantação dessa prática é baixo (10\%). Porém, $50 \%$ dos gestores informaram que a mesma está em processo de implantação (Tabela 4), o que tende a ampliar o nível efetivo de implantação da prática. 
Comunidades de prática ou Comunidades de conhecimento - que é uma prática de grande importância para as instituições de ensino por cumprir dois importantes papéis para a formação do capital humano: a transferência do conhecimento e a inovação (STEWART, 1998), sendo formadas através de alianças de pessoas formadas intencional ou espontaneamente para compartilhar, criar habilidades comuns, conhecimento e experiências (YOUNG, 2010) apresentou o pior resultado dentre todas as práticas analisadas. O nível efetivo de implantação dessa prática é baixo (Gráfico 1), pois nenhum dos gestores apontou a prática já implantada (estágio 3) ou implantada e apresentando resultados relevantes (estágio 4). Para esta prática, 30\% dos gestores informaram que não existem planos de implantação (estágio 0), 50\% deles apontaram que a prática está sendo planejada para implantação futura (estágio 1) e apenas $20 \%$ responderam que a prática está em processo de implantação (estágio 2). Como, no contexto educacional, as comunidades de prática "[...] são as ações de intervenções que envolvem o social, o convivo, a disseminação e o compartilhamento da informação e do conhecimento obtidos e apreendidos no contexto educacional" (URPIA et al., 2016, p. 81), o resultado compromete o objetivo final das instituições de ensino, que consiste em oferecer uma educação de qualidade para a sociedade.

\subsection{Análise do alcance das práticas}

Em relação ao alcance das práticas de recursos humanos nas escolas pesquisadas, observa-se que, na média, o nível efetivo de alcance é baixo (24\%), tal como demonstrado na Tabela 5. Quatro práticas contribuíram para este resultado, tal como pode ser observado no Gráfico 2: fóruns, coaching, mentoring e comunidades de prática. Já narrativas, universidade corporativa e educação corporativa foram práticas que apresentaram um nível efetivo de alcance médio.

Gráfico 2 - Nível efetivo de alcance das práticas de recursos humanos.

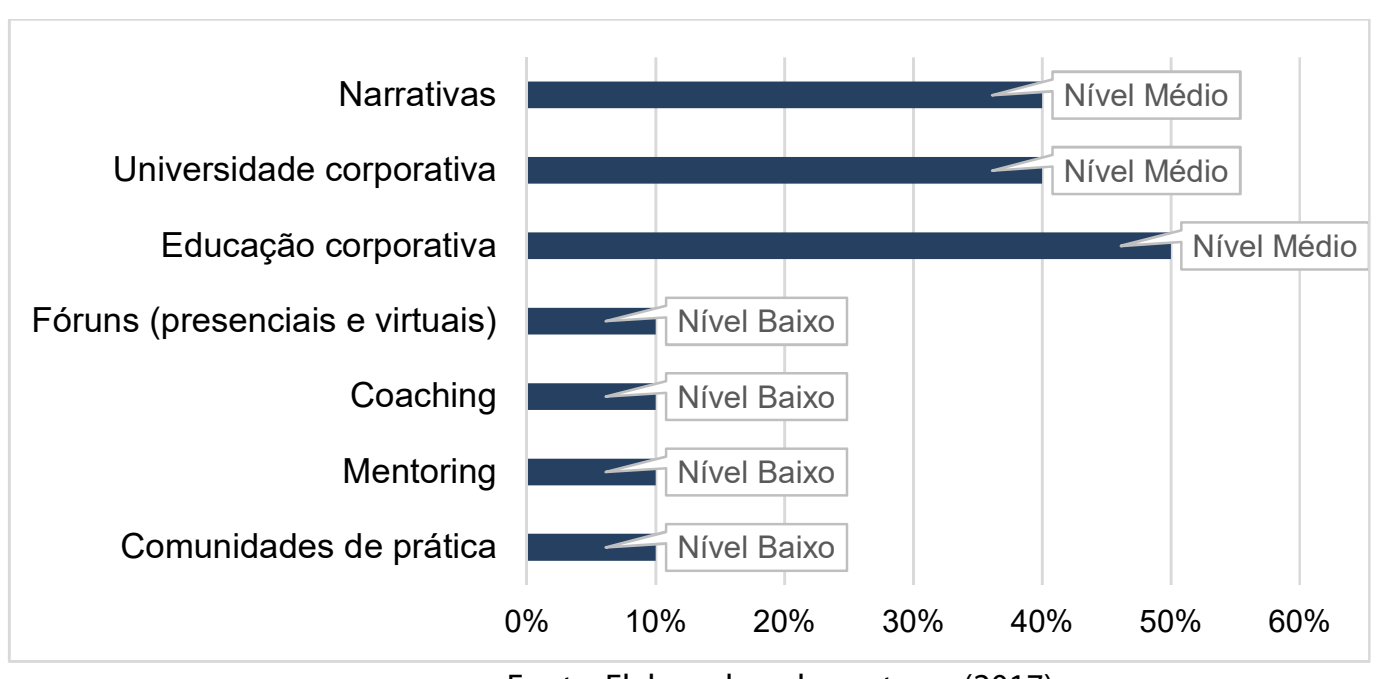

Fonte: Elaborado pelos autores (2017).

Tal se observa na Tabela 5, a prática também apresentou o pior resultado em relação ao nível de alcance, dado que $90 \%$ dos respondentes informaram que só há iniciativas isoladas dentro das suas instituições escolares. Os demais $10 \%$ dos gestores responderam que muitos departamentos usam essa prática.

Tabela 5 - Análise do alcance das ações ou práticas de recursos humanos

\begin{tabular}{|c|c|c|c|c|c|}
\hline \multirow{2}{*}{ Ação ou prática } & \multicolumn{5}{|c|}{ Alcance } \\
\hline & 1 & 2 & 3 & 4 & N/R \\
\hline Comunidades de prática/comunidades de conhecimento & $90 \%$ & $0 \%$ & $10 \%$ & $0 \%$ & $0 \%$ \\
\hline Mentoring & $70 \%$ & $20 \%$ & $0 \%$ & $10 \%$ & $0 \%$ \\
\hline Coaching & $50 \%$ & $20 \%$ & $0 \%$ & $10 \%$ & $20 \%$ \\
\hline Fóruns (presenciais e virtuais)/listas de discussão & $40 \%$ & $50 \%$ & $10 \%$ & $0 \%$ & $0 \%$ \\
\hline Educação corporativa & $30 \%$ & $20 \%$ & $40 \%$ & $10 \%$ & $0 \%$ \\
\hline Universidade corporativa & $30 \%$ & $20 \%$ & $40 \%$ & $0 \%$ & $10 \%$ \\
\hline Narrativas & $40 \%$ & $10 \%$ & $40 \%$ & $0 \%$ & $10 \%$ \\
\hline Médias & $50 \%$ & $20 \%$ & $20 \%$ & $4 \%$ & $6 \%$ \\
\hline
\end{tabular}

Fonte: Elaborado pelos autores (2017).

Nota: [1]: iniciativas isoladas dentro da organização; [2]: alguns departamentos usam a prática; [3]: muitos departamentos usam a prática, e; [4]: amplamente disseminada na organização. 
Em relação ao nível de alcance do mentoring, 70\% dos gestores informaram que só há iniciativas isoladas dentro das suas instituições escolares, enquanto $20 \%$ dos gestores responderam que alguns departamentos usam a prática. Já $10 \%$ dos respondentes apontaram que a prática está amplamente disseminada nas suas escolas. No que diz respeito à prática de coaching, $50 \%$ dos gestores informaram que só há iniciativas isoladas dentro das suas escolas e $20 \%$ apontaram que alguns departamentos usam a prática. Outros $20 \%$ dos gestores não responderam sobre o alcance dessa prática em suas instituições.

Quanto ao alcance da prática fóruns, 50\% dos gestores apontaram que alguns departamentos usam essa prática, enquanto $40 \%$ dos gestores indicaram que só há iniciativas isoladas dentro das suas escolas. Os $10 \%$ restantes dos gestores informaram que muitos departamentos usam a prática.

Dentre as práticas que apresentaram um nível efetivo médio de alcance, destaca-se educação corporativa. Essa prática teve $40 \%$ dos gestores informando que muitos departamentos usam a prática e 10\% deles indicando que a prática está amplamente disseminada na organização. Entretanto, 30\% dos respondentes apontaram que só há iniciativas isoladas dentro da organização e, para $20 \%$, alguns departamentos usam a prática.

\section{CONCLUSÃO}

Diante da contribuição que a GC em recursos humanos pode dar para as instituições de ensino, por auxiliar o gestor na construção de uma equipe com maior capacitação, algo que amplia a aprendizagem organizacional e, consequentemente, melhora a qualidade do ensino, o objetivo geral deste trabalho foi analisar o nível de implantação e de alcance das práticas de GC de recursos humanos em escolas públicas do município de Sarandi.

Para tal, inicialmente foi cálculado o alfa de Cronbach para os dados obtidos com a aplicação do instrumento de diagnóstico. A partir do cálculo do alfa de Cronbach tanto para todos os vinte e sete itens do instrumento de diagnóstico para os níveis de implantação e alcance quanto para apenas os sete itens da categoria de recursos humanos também para os níveis de implantação e alcance, verifica-se que o nível de consistência dos dados obtidos varia de moderada (para os sete itens que representam o nível de alcance das práticas de recursos humanos) para excelente (os demais casos), o que significa que as respostas decorrentes da aplicação do instrumento de diagnóstico aplicado têm uma alta confiabilidade. Diante da validade da escala e da sua confiabilidade, observa-se que a pesquisa realizada possui uma grande robustez.

Em seguida foram analisados os níveis de implantação e alcance das práticas de recursos humanos. Mesmo diante da importância que as práticas de GC de recursos humanos possuem para uma instituição de ensino, os resultados da pesquisa mostram que, na média, o nível efetivo de implantação dessas práticas é mediano (35\%). Em relação ao alcance dessas práticas nas escolas pesquisadas, observa-se que, na média, o nível efetivo de alcance é baixo (24\%).

Esses resultados demonstram a necessidade de criação de medidas para a ampliação da implementação e alcance das práticas de GC de recursos humanos nas escolas analisadas. Diante disso, para trabalhos futuros, observase a necessidade de discutir sobre quais medidas podem ser adotadas para tal. Outra perspectiva de trabalho futuro é analisar os níveis de implantação e alcance das práticas de GC de recursos humanos em escolas de outros municípios.

\section{REFERÊNCIAS}

ALBAGLI, S. Novos Espaços de Regulação na Era da Informação e do Conhecimento. Rio de Janeiro: Campus, 1999.

ALMEIDA, D; SANTOS, M. A. R. dos; COSTA, A. F. B. Aplicação do coeficiente alfa de Cronbach nos resultados de um questionário para avaliação de desempenho da saúde pública. ENCONTRO NACIONAL DE ENGENHARIA DE PRODUÇÃO, 30., 2010. Anais ... São Carlos: ENEP, 2010. p. 1-12.

BATISTA, E. de O. Sistemas de informação: o uso consciente da tecnologia para o gerenciamento. São Paulo: Saraiva, 2006.

BATISTA, E. de O. Modelo de gestão do conhecimento para a administração pública brasileira: como implementar a gestão do conhecimento para produzir resultados em benefício do cidadão. Brasília: Ipea, 2012.

BATISTA, F.F. et al. Gestão do conhecimento na administração pública. Texto para Discussão, n 1095 . Brasília: Ipea, 2005.

BATISTA, F. F. et al. Casos Reais de implantação do modelo de gestão do conhecimento para a administração pública brasileira. Texto para Discussão, n 1941. Brasília: Ipea, 2014.

BENTO, J. C. et al. Práticas da gestão do conhecimento em recursos humanos em instituição de ensino superior à distância. Espacios, v. 37, n. 29, p. 21-30, 2016. 
CASSIANO, N. D.; BARBOSA, M. de F.; MACUCH, R. da S. Desenvolvendo competências empreendedoras no ensino superior: potencializar e empoderar para transformar. In: PICANÇO, F. C. de A.; CARNEIRO, R. A.; PERIOTTO, T. T. C. Empreendedorismo sob a ótica da interdisciplinaridade. v.2. Maringá: Unicesumar, 2015. cap. 1.

CAVALCANTI, M. Gestão de Instituições na sociedade do conhecimento: um roteiro para a ação. Rio de Janeiro: Campus, 2001.

DAVENPORT, T. H.; PRUSAK, L. Conhecimento Empresarial. Rio de Janeiro: Campus, 1999.

HORA, H. R. M.; MONTEIRO, Gina T. R.; ARICA, J. Confiabilidade em Questionários para Qualidade: Um Estudo com o Coeficiente Alfa de Cronbach. Produto \& Produção, v. 11, n. 2, p. 85- 03, 2010.

LOESCHI, C.; HOELTGEBAUM, M. Métodos Estatísticos Multivariados. São Paulo: Saraiva, 2012.

MEISTER, J. C. Educação corporativa. São Paulo: Pearson Makron Books, 1999.

SÁNCHEZ , P.L. Aprendizaje Colaborativo para la Gestión de Conocimiento en Redes Educativas en la Web 2.0. 2011. Tesis (Doctoral) - Universidad Nacional de Educación a Distancia Facultad de Educación Departamento de Didáctica, Organización Escolar y Didácticas Especiales, Madrid, 2011.

SCHLESINGER, C. C. B. et al. Gestão do Conhecimento na Administração Pública. Curitiba: Instituto Municipal de Administração Pública - IMAP, 2008.

STEWART, T. A. A Riqueza do Conhecimento: O Capital Intelectual e a Organização do Século XXI. Rio de Janeiro: Campus, 2002.

STEWART, T. A. Capital Intelectual: a nova vantagem competitiva das empresas. 6. ed. Rio de Janeiro: Campus, 1998. YOUNG, R. Knowledge Management Tools and Techniques Manual. Tokio: Asian Productivity Organization (APO), 2010.

URPIA, A. G. B. da C. et al. A gestão do conhecimento nas escolas da Amusep. In: MENEGASSI, C. H. M. et al. (Org.). Gestão do conhecimento nas organizações: Inovação, Educação, tecnologias e Gestão. São Paulo: Gregory, 2016. cap. 3. 